\author{
Associate Professor Mihail-Dumitru SACALĂ, PhD \\ E-mail: mihai.sacala@csie.ase.ro \\ The Bucharest University of Economic Studies \\ Associate Professor Simona Roxana PĂTĂRLĂGEANU, PhD \\ E-mail: rpatarlageanu@eam.ase.ro \\ The Bucharest University of Economic Studies \\ Lecturer Maria-Floriana POPESCU, PhD \\ E-mail: maria.popescu@rei.ase.ro \\ The Bucharest University of Economic Studies \\ Marius CONSTANTIN, PhD Student (Corresponding author) \\ E-mail: marius.constantin@eam.ase.ro \\ The Bucharest University of Economic Studies
}

\title{
ECONOMETRIC RESEARCH OF THE MIX OF FACTORS INFLUENCING FIRST-YEAR STUDENTS' DROPOUT DECISION AT THE FACULTY OF AGRI-FOOD AND ENVIRONMENTAL ECONOMICS
}

\begin{abstract}
Students dropping out of higher education is a common issue many universities are facing all around the world. This paper complements the existing literature with a unique perspective on the mix of factors influencing firstyear students' dropout decision at the Faculty of Agri-Food and Environmental Economics from Bucharest, Romania. The objective of this research was to explore these factors through the lens of an unprecedented crisis caused by the COVID-19 pandemic. The ordinal logistic regression method was used based on data resulted from carrying out an online survey. The results of this econometric research can help decision-makers improve retention, the quality of education and the healthy integration of the first-year economics students in the university environment.

Keywords: higher education dropout; education abandonment; digital education; COVID-19 pandemic; risk factors; logistic regression
\end{abstract}

JEL Classification: I21, C31

\section{Introduction}

Economic educational institutions are essential in any society. Such educational providers generate transgenerational output through human capital formation with a unique economic touch with effects beyond the usual form of direct economic impact (Blackwell et al., 2002; Topalova \& Shvydka, 2020).

DOI: $10.24818 / 18423264 / 55.3 .21 .13$ 
Mihail-Dumitru Sacală, Simona Roxana Pătărlăgeanu, Maria-Floriana Popescu, Marius Constantin

Founded in 1913 and specialized in the fields of economic, administrative and social sciences, the Bucharest University of Economic Studies is one of the top research and education universities from Romania.

The Faculty of Agri-food and Environmental Economics is one of the 13 faculties within the Bucharest University of Economic Studies that offers undergraduate, master's, doctoral and post-doctoral degree programmes. All of them aim to shape future agri-food and environmental specialists in the field of economics in the context of European integration and sustainability. Through its programmers, the faculty develops analytical, managerial and entrepreneurial skills among students. However, the faculty is encountering a dropout rate in the case of first-year undergraduate students situated between $16 \%$ and $30 \%$. In general, students and their families encounter financial issues, especially in the case of the students coming from the rural areas of Romania. Due to the lack of financial resources, such students are forced by the conjuncture to look for a full-time jobs since the first year of study, which causes some of them to drop out of the higher education system eventually. Additionally, students who often encounter difficulties in adapting to the academic environment also develop an orientation towards not attending classes or being involved in any of projects launched at the initiative of the Faculty.

In the context of the COVID-19 pandemic, there is a concern about the potential emergence of many dropout cases among first-year students at The Faculty of Agri-food and Environmental Economics. This is justified by the fact that first-year students are exposed to some inequities-deepened the disparities between vulnerable students and those with a better socioeconomic status.

Considering the unprecedented socio-economic, sanitary and education global crisis caused by the COVID-19 pandemic (Peppou et al., 2020), the scientific interest for exploring the risk factors for higher education abandonment has risen, especially students are now more exposed than ever to the education digitalization process intensification caused by the COVID-19 pandemic. This paper complements the existing literature concerning the topic of higher education abandonment with a unique contribution, referring to the paper's specific focus: on the one hand, economics students, and, on the other hand, this paper is centered around the factors that significantly contribute to the students' decision to dropout. Moreover, this research expands the field of knowledge with a niche approach on topic of higher education abandonment by providing insight on the implications of the COVID-19 pandemic on the educational process in the case of the soon-to-be economist, currently first-year students at the Faculty of Agri-food and Environmental Economics in Romania; Bucharest University of Economic Studies.

The objective of this research is to examine the influence of risk-factors that can cause higher education abandonment based on first-year economics students of the Faculty of Agri-food and Environmental Economics who are facing even additional issues in successfully adapting to the academic environment due to the negative implications caused by the COVID-19 crisis. 
Econometric Research of the Mix of Factors Influencing First-year Students' Dropout Decision at the Faculty of Agri-food and Environmental Economics

This research paper follows a traditional format. The first part of the paper contains a short literature review, which is followed by the chapter dedicated to the description of the materials and methods used in carrying out this study. The results are included in the following chapter and then the discussion. In the last part of the paper, the conclusions of this research are highlighted, as well as the limitations. Not only that, but further research directions are also suggested.

\section{Literature Review}

Dropping out of higher education is caused by many and complex reasons, a phenomena which is not desirable neither for the student, nor for the University. From a certain point of view, higher education institutions are successful when students complete the education program they are enrolled in, in contrast to deficient student retention, which is an indicator that measures failure in regard to students successfully adapting to the academic environment (Wild \& Schulze Heuling, 2020). Students who encounter serious issues in managing stressors and who cannot overcome the initial challenges of adaptation to the higher education system are generally less involved in academic tasks, obtaining less academic achievement and satisfaction. Also, these students often expertise high levels of emotional exhaustion due to facing adaptation difficulties (Casanova et al., 2021).

The literature consists of many different approaches on at-risk student typologies in the face of abandoning the higher education system. Fortin et al. (2006) developed an analysis based on clustering subgroups in various at-risk student typologies: the anti-social covert student-typology; the uninterested in education student-typology; the depressive student-typology and the social adjustment difficulties student-typology. Student typology is a research topic worth studying, especially if connected and analyzed through the lens of financial status and behavior (Smeureanu et al., 2013; Ruxanda et al., 2018).

Mäkinen, Olkinuora, and Lonka (2004) carried out an analysis with a similar objective, but they divided students into three groups: study-oriented students, non-committed students and work-life balance-oriented students - only to come to the result that students' intentions to abandon education were connected with their educational orientation and that non-committed students were those who intended to abandon their high education studies altogether.

First-year university students are considered to be especially at risk in the face of dropout due to many reasons, including poor academic performance (Govender, 2020), resources (Romito et al., 2020) and pedagogical backgrounds (Bañeres et al., 2020), financial problems, family issues - especially in the case of online learning and many other factors.

Since March 2020, due to the COVID-19 crisis, many sectors of the economy were forced to adopt remote working if possible and the education system was affected the most (Narbut et al., 2020). eLearning has become a must for university all around the world during the COVID-19 Pandemic. The latter has 
Mihail-Dumitru Sacală, Simona Roxana Pătărlăgeanu, Maria-Floriana Popescu, Marius Constantin

rapidly accelerated predicted trends in information management and digitalization in education globally (Barnes, 2020).

Even before the global crisis caused by the COVID-19 pandemic, digitization had been considered of great importance with tremendous potential to foster sustainable development through creating an open and inspiring educational environment that has a significant contribution to the generation of economic growth (Voronova \& Novikova, 2019). Additionally, some universities take the role of leading the change toward an even more sustainable future by expanding to rural areas in regard to their campuses, as well as focusing on harnessing the positive aspects of digitalization (Popescu et al., 2020a). In Romania, the COVID19 pandemic has caught the higher education system in various stages of the digitalization process - some universities adapted faster than others based on regional wealth and resilience (Ignat \& Constantin, 2020) and on the regional performance in regard to accessing the European funds for rural development (Dinu et al., 2020). Romanian top universities have transitioned to eLearning very easily during the COVID-19 pandemic, mainly due to having a strong infrastructure (Edelhauser \& Lupu-Dima, 2020).

Fourie (2020) developed a cross-sectional quantitative study on the risk factors impacting first-year students' intention to abandon a university in South Africa using partial least squares structural modelling method. The outcomes show that it is not sufficient to address the direct effects leading to education drop out, but the indirect effects must also be identified and considered should one want to have success in solving the students' dropout issue.

Therefore, Fourie (2020) argues for the necessity to study the mix of factors that influence the students' higher education dropout decision in order to better understand how to mitigate this negative phenomena. By approaching the roots of the decision to dropout of the education system, one can aim for supporting students in the regards they are most vulnerable in. Taking this into account, the objective of this paper is harmonised with the previously explained approach of finding elements that can help students finish their studies. The research method was selected according to this arguments.

\section{Materials and methods}

In the case of Romania, Ivan et al. (2012) showed that the decision to dropout is influenced by factors such as: financial issues and family problems. This is also suggested by Popescu et al. (2020b). Other dropout predictors are the low degree of engagement in educational activities and in doing tasks, as well as the overall academic performance.

Students' Baccalaureate grades in math and economics represent important factors that influence the success rate of successfully finishing economic programs, as well as it can help determine how likely are certain students to encounter issues during the educational process. 
Econometric Research of the Mix of Factors Influencing First-year Students' Dropout Decision at the Faculty of Agri-food and Environmental Economics

Digital platforms and social media have become almost indispensable instruments for economic educators. Even though the latter have divergent visions on incorporating social media platforms in the educational act (Al-Bahrani et al., 2017), the full transition in the digital space caused by the COVID-19 pandemic has been pushing these divergent visions to a point of convergence, specific to embracing various digital solutions for engaging with students (including social media platforms). However, the pandemic is forcing students to adapt to being taught exclusively online. This could represent one of the stressor influencing students' dropout decision. The latter can also be influenced by the education background. Students with no economic background or economics-oriented students encounter difficulties after enrolling in a higher education program specific to the field of economics. Differences in prior education represent actual challenges not only for students, but for the teachers in higher education as well, because they have to decide which knowledge of economics the students have to catch up first.

Busom, Lopez-Mayan, and Panadés (2017) carried out a research focused on the correlation between college students' performance in tests and the newly learned tools. The results of their study confirmed that students who performed well in the tests assessing their knowledge of economic principles did not integrate the newly learned tools in an efficient manner in their economic thinking process. In this regard, grading policies and evaluating students' performance in the field of economics is challenging and it should be correlated not only with how well a student does in a test, but rather it should also be correlated with how students shape their way of thinking - Are they approaching multidimensional economic facets of issues? In this regard, it is important for teachers to adapt their evaluation methods in relation with the students' academic and professional needs in their livees as a future successful economists. By doing that, the dropout decision would be positively impacted and the students would be encouraged to complete their economic studies, as they have a direct correspondence with the reality of the socio-economic life.

In accordance with the objective of this research, the previously explained factors were taken into consideration when selecting the research method. Based on this foundation, a survey was designed in order to examine the influence power of selected risk-factors that can cause economics students to dropout of the bachelor program. Survey data were collected at the end of 2020 using through Google Forms.

There were 176 responses $(\mathrm{N}=176)$ that were registered from the first-year students of Faculty of Agri-food and Environmental Economy. In order to study the mix of factors influencing the Faculty of Agri-food and Environmental students' dropout decision, the logistic regression method was selected for carrying out the research. At the beginning of the 2020-2021 academic year, the Faculty had 336 first-year students enrolled at the Bachelor's programme. Therefore, for a population size of 336 first-year students and a margin of error of $5.1 \%$, the sample 
Mihail-Dumitru Sacală, Simona Roxana Pătărlăgeanu, Maria-Floriana Popescu, Marius Constantin

size is 176 students. Collected data was processed and coded to be suitable for designing logistic regression models in SPSS. The following variables were considered for the design of the logistic regression models:

- EMP (Employment) - It is a binary variable used for expressing if the responding student is currently employed (coded with 1) or not (coded with 0 ).

- GRD (Graduation) - It is a binary variable used for expressing if the student has obtained an overall grade less than 7 out of 10 (coded with 1) or not (coded with 0) at the national Baccalaureate (high school graduation).

- LFC (Family with low income) - Binary variable used for expressing if the student is part of a family with low income (code: 1 ) or not (code: 0 ).

- OPH (Orphan) - It is a binary variable used for expressing if the student is orphan (coded with 1 ) or not (coded with 0$)$.

- DEMP (Desire for employment) - It is a binary variable used for expressing if the student is motivated (coded with 1) or not (coded with 0 ) to graduate the economic bachelor program in order to find a well-paid job.

- SVD (Social validation) - It is a binary variable used for expressing if the student is motivated (coded with 1) or not (coded with 0 ) to graduate the economic bachelor program in order to obtain social validation (code: 1) or not (code: 0 ).

- PLV (Residence) - It is a binary variable used for expressing if the student is currently living in the urban area (code: 1) or in a rural area (code: 0 ).

- KNW (Desire for knowledge) - It is a binary variable used for expressing if the student is motivated (coded with 1 ) or not (coded with 0 ) to graduate the economic bachelor program in order to improve themselves by learning more (coded with 1) or not (coded with 0 ).

- NOA (The negative impact of the full transition of the education process in the digital space due to the COVID-19 pandemic on the student-perceived quality of received education) - It is an ordinal qualitative variable used for expressing if the student perceives in a negative manner the transition from the inclass learning activities to the online classes. The perceived minimum negative impact was coded with 1 and the perceived maximum negative impact with 5 .

- LSI (Lack of social interaction) - It is an ordinal qualitative variable used for expressing how the student perceives the lack or poor quality of the social interaction in the online environment with colleagues. The perceived best quality of online social interaction with colleagues was coded with 1 and the perceived poor online social interaction was coded with 3.

- TCH (Online teaching activities quality) - It is an ordinal qualitative variable used for expressing how the student perceives the quality of the online teaching activities. The perceived best quality of the online teaching activities was coded with 1 and the perceived poor quality was coded with 3 .

- CTH (Interaction with teachers) - It is an ordinal qualitative variable used for expressing how the student perceives the quality of the online interactions with teachers. The perceived best quality of the online interactions with teachers was coded with 1 and perceived poor quality was coded with 3 . 
Econometric Research of the Mix of Factors Influencing First-year Students' Dropout Decision at the Faculty of Agri-food and Environmental Economics

- PDV (Personal development) - It is an ordinal qualitative variable used for expressing how much a student is motivated to graduate the economic bachelor program in order to have a proper personal development. The expressed minimum desire was coded with 1 and the max was coded with 3 .

- PFDV (Professional development) - It is an ordinal qualitative variable used for expressing how much a student is motivated to graduate the economic bachelor program for a proper professional development. The expressed minimum desire was coded with 1 and the max was coded with 3 .

- ADV (Academic development) - It is an ordinal qualitative variable used for expressing how much a student is motivated to graduate the economic bachelor program for a proper academic development. The expressed minimum desire was coded with 1 and the max was coded with 3 .

In order to quantify the impact of exogenous variables on the following endogenous variables: NOA, EMP, PDV, PFDV, ADV, the ordinal and binary logistic regression methods were used, depending on the type of dependent variable. The binary logistic regression requires the dependent variable to be binary and ordinal logistic regression requires the dependent variable to be ordinal. The models designed in this study include both binary and ordinal dependent variables. The second model is a binary logistic regression, where the dependent variable is dummy ( 0 for no and 1 for yes). The rest of four remaining models are ordinal regression models with ordinal qualitative dependent variables as they were presented earlier (coded from 1 to 5 or from 1 to 3 ).

The logistic regression requires that the independent variables should be either continuous or categorical. The models designed in this study include only categorical independent variables, binary or ordinal, as they were presented earlier, dummy or scaled from 1 to 5 or from 1 to 3 .

Additionally, the logistic regression requires the observations to be independent of each other. In other words, the observations collected do not come from repeated measurements or matched data. The independence is guaranteed by the manner in which the survey was created and used through questions that do not repeat and do not measure the same indicators. The logistic regression also requires to be little or no multicollinearity among the independent variables. This assumption have been tested using Variance Inflation Factor (VIF), which estimates how much the variance of a coefficient is inflated because of the dependence with other predictors. A value above 10 for VIF is indicating multicollinearity. For the models in this study, the values for VIF are all around 1, between 1.003 and 1.466 , proving that there is no multicollinearity in any designed model. Moreover, the logistic regression assumes linearity of independent variables and $\log$ odds. Although this analysis does not require the dependent and independent variables to be related linearly, it requires that the independent variables are linearly related to the log odds. In order to test this assumption, the test of parallel lines was used using SPSS software, in the case of each ordinal logistic regression model. This test compares the ordinal model which has one set 
Mihail-Dumitru Sacală, Simona Roxana Pătărlăgeanu, Maria-Floriana Popescu, Marius Constantin

of coefficients for all thresholds to a model with a separate set of coefficients for each threshold. For models III, IV and V, the p-value is above 0.05 and the null hypothesis that states that the location parameters (slope coefficients) are the same across response categories is accepted. For the first model, the p-value is lower than 0.05. However, the test of the proportional odds assumption has been described as anti-conservative, it nearly always results in rejection of the proportional odds assumption, particularly when the number of explanatory variables is large, the sample size is large or there is a continuous explanatory variable in the model. Thus, it is advisable to examine the data using a set of separate logistic regression equations to explicitly see how the ORs vary at the different thresholds. In these cases where the dependent variable was tested with an independent variable individually, the p-value is still not larger than 0.05 , but significantly different from 0 . For example, it can be as high as 0.038 for TCH. However, based on contingency results, a lower value for the test of parallel lines do not automatically means that the null hypothesis should be rejected.

\section{Results and discussions}

\subsection{Logistic Regression Model I}

The first ordinal logistic regression model was designed to analyze the relationship between the negative impact of the full transition of the education process in the digital space due to the COVID-19 pandemic on the studentperceived quality of received education (NOA, dependent variable) and 5 factors (independent variables): residence of students (PLV), lack of social interaction (LSI), perceived quality of online teaching activities (TCH), perceived quality of the interactions with teachers $(\mathrm{CTH})$ and the overall grade obtained at the national Baccalaureate (GRD). Looking at model fitting information, it can be noticed that the model gives better prediction than a prediction based on the marginal probabilities for the outcome (p-value $<0.05)$. The Goodness of fit test indicates that the null hypothesis (the model fits the data well) should be rejected (p-value $<0.05)$. However, a lower p-value does not automatically mean that the model is not appropriate. For models with a large number of categorical predictors, the test is not very reliable. In order to estimate the proportion of variance in the outcome that can be accounted for by the explanatory variables, there are computed three approximations of R2. For this model, value of Nagelkerke indicates that the 5 factors explain only $33 \%$ of the variation between the negative impact of the full transition of the education process in the digital space due to the COVID-19 pandemic on the student-perceived quality of received education categories. Although there are other factors which have a major influence on students' perceptions, the current model still includes significant explanatory variables.

The table of parameters estimates indicates the sign and the power of the relationship between variables. Using Wald test, the null hypothesis is rejected and it is concluded that all parameters are statistically significant ( $p$-value $<0.05$ ). 
Econometric Research of the Mix of Factors Influencing First-year Students' Dropout Decision at the Faculty of Agri-food and Environmental Economics

Moreover, variables PLV, CTH and GRD indicate a negative relation while LSI and TCH a positive relation. It can be concluded that students living in urban areas are less likely to feel a significant negative impact of the transition to the online learning activities compared to the students who live in rural areas. One cause could be the fact that the internet infrastructure in the rural areas could be deficient sometimes and could interfere in the educational process. If students perceive their online interaction with teachers as poor, then the negative impact of the full transition of the education process in the digital space on the student-perceived quality of student-perceived received education will be bigger, because the learning process is hindered by the lack of efficient communication and students must learn more by themselves. On top of that, if teachers give students more assignments, the lack of social interaction corroborated with the assignments pressure can be a sufficient push for the students to decide to abandon the economic higher education program. Not being physical present in the same classroom and not being able to have a physical communication with teachers or fellow students has caused the respondents to experience a heavier process of integrating in the Bucharest University of Economic Studies community. Considering that the respondents are first-year students, their feeling of belonging to the Faculty and University has not developed as much as in the case of previous generations of students. This can make a difference for the current first-year students when deciding to continue their higher education progress or not. From this point of view, the COVID-19 pandemic has had a deeply negative impact on the integration of first-year students in the academic community.

\subsection{Logistic Regression Model II}

The second ordinal logistic regression model was designed to analyze the relationship between the students' employment status (EMP, dependent variable) and 2 factors (independent variables): the overall grade obtained at the national Baccalaureate (GRD) and students' motivation to gradute the economic bachelor program in order to obtain social validation (SVD). According to the model summary, the value of Nagelkerke indicates that these 2 factors explain only $9 \%$ of the variation between the employment status categories. Additionally, this indicates that there are other factors that have a major influence on students' perceptions and that this model includes only a small part of significant explanatory variables.

Both explanatory variables indicate a positive relation with the dependent variable. Thus, for a student that has been admitted at the bachelor program of the Faculty of Agri-food and Environmental Economics with a grade lower than 7, then for that student it is likely to have had already a job, a decision which was also influenced by the need for social validation. Thus, having a personal source of income is mainly determined by being perceived as independent in society and represents an alternative for those who do not want to actively participate in educational activities. Having a full-time job while being enrolled at an economic bachelor program diminishes the available time for learning and for attending 
Mihail-Dumitru Sacală, Simona Roxana Pătărlăgeanu, Maria-Floriana Popescu, Marius Constantin

classes, even if online. Combined with the fact that these students have a precedent and they did not obtain good grades at the national Baccalaureate, then it can be expected that these same students might have tendencies for considering dropping out of school in order to focus on their full-time job and on seeking social validation through hard work and being performant at their employer, rather than focusing on the finishing their economic studies.

\subsection{Logistic Regression Model III}

The third ordinal logistic regression model was designed with the purpose of analyzing the relationship between the desire for personal development (PDV, dependent variable) and 2 factors (independent variables), being orphan (OPH) and being part of a family with low income (LFC). Based on the model fitting SPPS output, one can notice that the model gives better prediction than a prediction based on the marginal probabilities for the outcome (p-value $<0.05$ ). The Goodness of fit test indicates that the null hypothesis should not be rejected. Thus, it can be concluded that the data and the model predictions are similar and the model is good. Nagelkerke indicates that these 2 factors explain only $4 \%$ of the variation between the desire for personal development categories.

The OPH variable indicates a negative relation while LFC variable indicates a positive relation. This means that students may have a stronger desire for personal development if they come from a family with low income, but this desire may be diminished if they are orphans. Having few possibilities, such students want to have a healthy personal development, not only from the perspective of the finishing the economic bachelor program they are enrolled in, but the unfavorable social conjuncture could cause trouble and could be representative for a typology of students who are more likely to dropout.

\subsection{Logistic Regression Model IV}

The forth ordinal logistic regression model was elaborated with the objective of analyzing the relationship between the desire of professional development (PFDV, dependent variable) and 2 factors (independent variables): desire for employment (DEMP) and desire for knowledge (KNW). Based on the model fitting information, one can notice that the model gives better prediction than a prediction based on the marginal probabilities for the outcome ( $p$-value $<0.05$ ). The Goodness of fit test indicates that the $\mathrm{H}_{0}$ should not be rejected. Thus, it can be concluded that the data and the model predictions are similar and the model is good. Nagelkerke indicates that these 2 factors explain only $7 \%$ of the variation between the desire for professional development categories.

This model shows that students might have a stronger desire for professional development if they wants to improve their knowledge in the field of economy or if they are determined to have a job after bachelor program graduation. It can be concluded that searching for a good job or being interested in the studied economic subjects may influence students to be more concerned about their 
Econometric Research of the Mix of Factors Influencing First-year Students' Dropout Decision at the Faculty of Agri-food and Environmental Economics

professional development at the Faculty of Agri-food and Environmental Economics. Chances for abandoning the higher education system in the case of the analyzed students per the fifth econometric model are small. The analyzed independent variable is positively correlated with the dependent variables, specific to the desire for employment and desire for knowledge.

\subsection{Logistic Regression Model V}

The fifth ordinal logistic model was designed in order to analyze the relationship between the desire of academic development (ADV, dependent variable) and 2 factors (independent variables): desire for employment (DEMP) and the orphan-factor $(\mathrm{OPH})$. According to the model fitting information, one can notice that the model gives better prediction than a prediction based on the marginal probabilities for the outcome ( $p$-value $<0.05$ ). The Goodness of fit test indicates that the null hypothesis should not be rejected. Thus, it can be concluded that the data and the model predictions are similar and the model is good. Nagelkerke indicates that these 2 factors explain only $9 \%$ of the variation between the desire for academic development categories.

The DEMP variable indicates a positive relation while the OPH variable indicates a negative relation. These relations express that students may have a stronger desire for their academic development if they are also motivated to get employed after graduation, but the motivation can be diminish if the same students are facing family issues.

\section{Conclusions}

First-year economics students dropping out of higher education is a sensitive topic in the case many universities, especially in case of developing countries where the COVID-19 pandemic has brought more negative than positive effects in terms od education conditions.

In this paper, the risk-factors that can cause higher education dropout were examined in the case of first-year economics students at the Faculty of Agri-food and Environmental Economics from Bucharest, Romania. Five logistic regression models were designed with the aim of studying the mix of factors influencing economics students' dropout decision, based on the influence power of each factor during an unprecedented time of crisis caused by the COVID-19 pandemic.

The parameters and coefficients of the designed logistic regression models are statistically significant and the variations of the dependent variables are explained up to $33 \%$. The models are valid and the analysis of the analyzed variables has proved causality. In this regard, this research can be used by decisionmakers for improving the quality of education and for preventing academic dropout in the case of first-year economics students. Since this research is specific to a time of crisis caused by the COVID-19 pandemic, the results are even more valuable, mainly because students have never faced such an stressor before. The results of 
Mihail-Dumitru Sacală, Simona Roxana Pătărlăgeanu, Maria-Floriana Popescu, Marius Constantin

this research can represent a point of reference for anticipating economics students' reaction in the face of future times of crisis, as well as this research can help mitigating the negative effects of such situations on the students' dropout decision.

Results confirm that students living in urban areas are less likely to feel a significant negative impact of the transition to the online learning activities compared to the students who live in rural areas. If students perceive their online interaction with teachers as poor, then the negative impact of the online transition will be more impactful, and, on top of that, if teachers give students more assignments, the lack of social interaction corroborated with the assignments pressure can be a sufficient push for the students to decide to abandon the economic higher education program. Additionally, not being physical present and not being able to have an in-person communication with teachers or fellow students can cause students to encounter issues in developing a healthy academic integration process. This can make a difference for the current first-year students if they are doubting continuing their higher education economic studies. From this perspective, the COVID-19 pandemic has had a deeply negative impact on the integration of first-year students in the academic community of the Bucharest University of Economic Studies.

There are many factors that can significantly influence the students' decision to dropout. In this regard, the following mix of factors proved to be most representative: the need for social validation through being employed and earning money in the case of the students admitted with below-average grades at the national Baccalaureate, the need to feel personal development progress outside the University in the case of students facing unfavorable social conditions and the need to feel professional development progress outside the University in the case of students eager to find a full-time job rapidly.

This study can be extended and improved in many ways. A possible direction would be taking more variables into considerations and testing more regression models, not only logistic ones, all with the aim of studying the dynamics of factors influencing economics students' dropout decision. Moreover, this research method can be easily replicated and applied on students from different institutions. The results could help decision-makers find best solution on how to support students efficiently and mitigate the higher education dropout phenomena.

\section{REFERENCES}

[1] Al-Bahrani, A., Patel, D. \& Sheridan, B. J. (2017), Have Economic

Educators Embraced Social Media as a Teaching Tool? The Journal of Economic Education, 48(1), 45-50. https://doi.org/10.1080/00220485.2016.1252290;

[2] Bañeres, D., Rodríguez, M. E., Guerrero-Roldán, A. E. \& Karadeniz, A. (2020), An Early Warning System to Detect At-Risk Students in Online Higher Education. Applied Sciences, 10(13), 4427; 
Econometric Research of the Mix of Factors Influencing First-year Students' Dropout Decision at the Faculty of Agri-food and Environmental Economics

[3] Barnes, S. J. (2020), Information Management Research and Practice in the Post-COVID-19 World. International Journal of Information Management, 55, 102175. https://doi.org/10.1016/j.ijinfomgt.2020.102175;

[4] Blackwell, M., Cobb, S. \& Weinberg, D. (2002), The Economic Impact of Educational Institutions: Issues and Methodology. Economic Development Quarterly, 16(1), 88-95. https://doi.org/10.1177/0891242402016001009;

[5] Busom, I., Lopez-Mayan, C. \& Panadés, J. (2017), Students' Persistent Preconceptions and Learning Economic Principles. The Journal of Economic Education, 48(2), 74-92. https://doi.org/10.1080/00220485.2017.1285735;

[6] Casanova, J. R., Gomes, C. M. A., Bernardo, A. B., Núñez, J. C. \& Almeida, L. S. (2021), Dimensionality and Reliability of a Screening Instrument for Students At-Risk of Dropping out from Higher Education. Studies in Educational Evaluation, 68, https://doi.org/10.1016/j.stueduc.2020.100957; [7] Dinu, M., Pătărlăgeanu, S. R., Chiripuci, B. \& Constantin, M. (2020), Accessing the European Funds for Agriculture and Rural Development in Romania for the 2014-2020 Period. Proceedings of the International Conference on Business Excellence, 14(1), 717-727. https://doi.org/10.2478/picbe-2020-0068; [8] Edelhauser, E. \& Lupu-Dima, L. (2020), Is Romania Prepared for eLearning during the COVID-19 Pandemic? Sustainability, 12(13), 5438. https://doi.org/10.3390/su12135438;

[9] Fortin, L., Marcotte, D., Potvin, P., Royer, É. \& Joly, J. (2006), Typology of Students At Risk of Dropping out of School: Description by Personal, Family and School Factors. European Journal of Psychology of Education, 21(4), 363. https://doi.org/10.1007/BF03173508;

[10] Fourie, C. M. (2020), Risk Factors Associated with First-Year Students' Intention to Drop out from a University in South Africa. Journal of Further and Higher Education, 44(2), 201-215;

[11] Govender, C. M. (2020), Hopes, Challenges and Goals_-Voices of FirstYear At-Risk Higher Education Students in South Africa. South African Review of Sociology, 51(1), 55-69;

[12] Ignat, R. \& Constantin, M. (2020), Multidimensional Facets of Entrepreneurial Resilience during the COVID-19 Crisis through the Lens of the Wealthiest Romanian Counties. Sustainability, 12(23), 10220.

https://doi.org/10.3390/su122310220;

[13] Ivan, L., Pricopie, R., Frunzaru, V., Cismaru, D. \& Nicoleta Corbu (2012), The Risk of Dropping Education for Romanian High School Students. Structural Factors and Educational Policies. Procedia - Social and Behavioral Sciences, 46, 2312-2321. https://doi.org/10.1016/j.sbspro.2012.05.477;

[14] Mäkinen, J., Olkinuora, E. \& Lonka, K. (2004), Students at Risk:

Students' General Study Orientations and Abandoning/Prolonging the Course of Studies. Higher Education, 48(2), 173-188;

[15] Narbut, N. P., Aleshkovski, I. A., Gasparishvili, A. T., Krukhmaleva, O. V. (2020), Forced Shift to Distance Learning as an Impetus to Technological 
Mihail-Dumitru Sacală, Simona Roxana Pătărlăgeanu, Maria-Floriana Popescu, Marius Constantin

Changes in the Russian Higher Education. RUDN Journal of Sociology, 20(3), 611-621. https://doi.org/10.22363/2313-2272-2020-20-3-611-621; [16] Park, J.-H. \& Choi, H. J. (2009), Factors Influencing Adult Learners' Decision to Drop Out or Persist in Online Learning. Educational Technology \& Society, 12(4), 207-217;

[17] Peppou, L. E., Economou, M., Skali, T. \& Papageorgiou, C. (2020), From Economic Crisis to the COVID-19 Pandemic Crisis: Evidence from a Mental Health Helpline in Greece. European Archives of Psychiatry and Clinical Neuroscience, 1-3. https://doi.org/10.1007/s00406-020-01165-4;

[18] Popescu, M.-F., Chiripuci, B.-C., Orîndaru, A., Constantin, M., \& Scrieciu, A. (2020a), Fostering Sustainable Development through Shifting Toward Rural Areas and Digitalization-The Case of Romanian Universities. Sustainability, 12(10), 4020. https://doi.org/10.3390/su12104020;

[19] Popescu, M.-F., Constantin, M., Chiripuci, B. (2020b), Large Private Companies: A Stimulus for the Marriage Rate Under the Premises of Job Security - The Case of the Romanian Counties. Journal of Economic Computation and Economic Cybernetics Studies and Research. 54(3), 215-230; [20] Romito, M., Pilutti, S. \& Contini, D. (2020), Why Do Students Leave University? Qualitative Research at an Italian Higher Education Institution. European Journal of Education, 55(3), 456-470;

[21] Ruxanda, G., Zamfir, C. \& Muraru, A. (2018), Predicting Financial Distress for Romanian Companies. Technological and Economic Development of Economy, 24(6), 2318-2337. https://doi.org/10.3846/tede.2018.6736; [22] Smeureanu, I., Ruxanda, G. \& Badea, L.M. (2013), Customer Segmentation in Private Banking Sector Using Machine Learning Techniques. Journal of Business Economics and Management, 14(5), 923-939;

[23] Topalova, S. \& Shvydka, O. (2020), Social Responsibility of Institutions of Higher Economic Education in the Context of the University Mission

Realization. Financial and Credit Activity-Problems of Theory and Practice, 2(33), 585-592. https://doi.org/10.18371/fcaptp.v2i33.207249;

[24] Voronova, T. A. \& Novikova, E. S. (2019), Dynamics of Higher Education and Social and Economic Indicators Globally in Conditions of Digitalization. Vision 2025: Education Excellence and Management of Innovations Through Sustainable Economic Competitive Advantage, 1992-1999;

[25] Wild, S. \& Schulze Heuling, L. (2020), Student Dropout and Retention: An Event History Analysis among Students in Cooperative Higher Education. International Journal of Educational Research, 104, 101687. 
Econometric Research of the Mix of Factors Influencing First-year Students' Dropout Decision at the Faculty of Agri-food and Environmental Economics

\section{APPENDIX}

Model I: The negative impact of the full transition of the education process in the digital space due to the COVID-19 pandemic on the student-perceived quality of education (NOA). Link function: Logit.

\begin{tabular}{|l|l|l|l|l|}
\hline Model Fitting Information & $-\mathbf{2}$ Log Likelihood & $\chi^{2}$ & df & Sig. \\
\hline Model & 364.195 & & & \\
\hline Intercept Only & 298.517 & 65.679 & 5 & 0.000 \\
\hline Final & \multicolumn{5}{|l|}{} \\
\hline Goodness-of-Fit & $\chi^{2}$ & df & Sig. \\
\hline Model & 379.886 & 271 & 0.000 \\
\hline Pearson & 232.173 & 271 & 0.958 \\
\hline Deviance & & & \\
\hline Pseudo $\mathbf{R}^{\mathbf{2}}$ & 0.311 & \multicolumn{3}{|l|}{} \\
\hline Cox and Snell & 0.333 & \\
\hline Nagelkerke & 0.137 & \\
\hline McFadden &
\end{tabular}

\begin{tabular}{|c|c|c|c|c|c|c|c|}
\hline \multicolumn{8}{|c|}{ Parameter Estimates } \\
\hline & & \multirow[b]{2}{*}{ Estimate } & \multirow{2}{*}{$\begin{array}{l}\text { Std. } \\
\text { Error }\end{array}$} & \multirow[b]{2}{*}{ Wald } & \multirow[b]{2}{*}{ Sig. } & \multicolumn{2}{|c|}{$95 \% \mathrm{CI}$} \\
\hline & & & & & & $\begin{array}{l}\text { Lower } \\
\text { Bound }\end{array}$ & $\begin{array}{l}\text { Upper } \\
\text { Bound }\end{array}$ \\
\hline \multirow{4}{*}{ 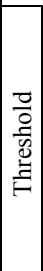 } & $\begin{array}{c}\text { Negative_impact_on } \\
\text { online_activities }=1]\end{array}$ & -3.224 & 1.134 & 8.089 & 0.004 & -5.446 & -1.002 \\
\hline & $\begin{array}{l}\text { [Negative_impact_on } \\
\text { online activities }=2 \text { ] }\end{array}$ & -2.103 & 1.107 & 3.606 & 0.058 & -4.273 & 0.068 \\
\hline & $\begin{array}{l}\text { [Negative_impact_on } \\
\text { online_activities }=3 \text { ] }\end{array}$ & -0.509 & 1.104 & 0.212 & 0.645 & -2.674 & 1.656 \\
\hline & $\begin{array}{l}\text { [Negative_impact_on } \\
\text { online_activities }=4]\end{array}$ & 0.799 & 1.106 & 0.522 & 0.470 & -1.368 & 2.966 \\
\hline \multirow{5}{*}{ 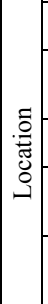 } & Place_of_living & -0.600 & 0.309 & 3.764 & 0.052 & -1.207 & 0.006 \\
\hline & $\begin{array}{l}\text { Lack_of_social_ } \\
\text { interaction }\end{array}$ & 0.723 & 0.247 & 8.604 & 0.003 & 0.240 & 1.207 \\
\hline & Teaching_activities & 0.728 & 0.273 & 7.090 & 0.008 & 0.192 & 1.264 \\
\hline & $\begin{array}{l}\text { Connection_with_ } \\
\text { teachers }\end{array}$ & -0.602 & 0.181 & 11.053 & 0.001 & -0.956 & -0.247 \\
\hline & $\begin{array}{l}\text { Graduation_grade_ } \\
\text { less than } 7\end{array}$ & -0.813 & 0.316 & 6.610 & 0.010 & -1.433 & -0.193 \\
\hline
\end{tabular}


Mihail-Dumitru Sacală, Simona Roxana Pătărlăgeanu, Maria-Floriana Popescu, Marius Constantin

\begin{tabular}{|c|c|c|c|c|c|c|c|}
\hline \multicolumn{2}{|c|}{ Coefficients. Dependent Variable: NOA } \\
\hline \multirow{3}{*}{ Model } & $\begin{array}{c}\text { Unstandardized } \\
\text { Coefficients }\end{array}$ & $\begin{array}{c}\text { Standardized } \\
\text { Coefficients }\end{array}$ & \multirow{2}{*}{ t } & \multirow{2}{*}{ Sig. } & \multicolumn{2}{|c|}{$\begin{array}{c}\text { Collinearity } \\
\text { Statistics }\end{array}$} \\
\cline { 2 - 5 } & B & $\begin{array}{c}\text { Std. } \\
\text { Error }\end{array}$ & Beta & & & $\begin{array}{c}\text { Toleran } \\
\text { ce }\end{array}$ & VIF \\
\hline (Constant) & 3.817 & 0.560 & & 6.812 & 0.000 & & \\
\hline PLV & -0.352 & 0.157 & -0.147 & -2.246 & 0.026 & 0.976 & 1.025 \\
\hline LSI & 0.385 & 0.130 & 0.231 & 2.952 & 0.004 & 0.685 & 1.459 \\
\hline TCH & 0.282 & 0.139 & 0.159 & 2.026 & 0.044 & 0.682 & 1.466 \\
\hline CTH & -0.289 & 0.085 & -0.249 & -3.386 & 0.001 & 0.773 & 1.293 \\
\hline GRD & -0.422 & 0.164 & -0.170 & -2.569 & 0.011 & 0.958 & 1.044 \\
\hline
\end{tabular}

Model II: Employment status (EMP) analysis

\begin{tabular}{|l|c|c|c|}
\hline \multicolumn{4}{|l|}{ Omnibus Tests of Model Coefficients } \\
\hline & $\chi^{\mathbf{2}}$ & df & Sig \\
\hline Step & 9.772 & 2 & 0.008 \\
\hline Block & 9.772 & 2 & 0.008 \\
\hline Model & 9.772 & 2 & 0.008 \\
\hline Model Summary & \multicolumn{3}{|}{} \\
\hline-2 Log likelihood & \multicolumn{3}{|l}{} \\
\hline Cox \& Snell $\mathrm{R}^{2}$ & \multicolumn{3}{|l}{} \\
\hline Nagelkerke $\mathrm{R}^{2}$ & \multicolumn{4}{|l}{0.054 .088} \\
\hline
\end{tabular}

\begin{tabular}{|l|c|c|c|c|c|c|}
\hline Variables in the Equation & B & S.E. & Wald & df & Sig. & $\operatorname{Exp(B)}$ \\
\hline Graduation_grade_less_than_7 & 0.879 & 0.418 & 4.415 & 1 & 0.036 & 2.408 \\
\hline Social_validation & 1.330 & 0.495 & 7.209 & 1 & 0.007 & 3.780 \\
\hline Constant & -2.094 & 0.311 & 45.381 & 1 & 0.000 & 0.123 \\
\hline
\end{tabular}


Econometric Research of the Mix of Factors Influencing First-year Students' Dropout Decision at the Faculty of Agri-food and Environmental Economics

\begin{tabular}{|c|c|c|c|c|c|c|c|}
\hline \multicolumn{3}{|c|}{ Coefficients. Dependent Variable: EMP } \\
\hline \multirow{3}{*}{ Model } & $\begin{array}{c}\text { Unstandardized } \\
\text { Coefficients }\end{array}$ & $\begin{array}{c}\text { Standardized } \\
\text { Coefficients }\end{array}$ & \multirow{2}{*}{ t } & \multirow{2}{*}{ Sig. } & \multicolumn{2}{|c|}{$\begin{array}{c}\text { Collinearity } \\
\text { Statistics }\end{array}$} \\
\cline { 2 - 4 } & B & $\begin{array}{c}\text { Std. } \\
\text { Error }\end{array}$ & Beta & & & $\begin{array}{c}\text { Toleran } \\
\text { ce }\end{array}$ & VIF \\
\hline (Constant) & 0.106 & 0.038 & & 2.829 & 0.005 & & \\
\hline PLV & 0.129 & 0.061 & 0.157 & 2.120 & 0.035 & 0.986 & 1.014 \\
\hline LSI & 0.228 & 0.082 & 0.206 & 2.780 & 0.006 & 0.986 & 1.014 \\
\hline
\end{tabular}

Model III: Personal development (PDV) analysis. Link function: Logit.

\begin{tabular}{|l|l|l|l|l|}
\hline Model Fitting Information & $-\mathbf{2}$ Log Likelihood & $\chi^{\mathbf{2}}$ & df & Sig. \\
\hline Model & 34.861 & & & \\
\hline Intercept Only & 28.288 & 6.574 & 2 & .037 \\
\hline Final & \multicolumn{4}{l|}{} \\
\hline Goodness-of-Fit & $\chi^{\mathbf{2}}$ & df & Sig. \\
\hline Model & 3.511 & 4 & .476 \\
\hline Pearson & 3.669 & 4 & .453 \\
\hline Deviance & & 4 & \\
\hline Pseudo R & & & \\
\hline Cox and Snell & 0.037 & & \\
\hline Nagelkerke & 0.042 & & \\
\hline McFadden & 0.018 & \\
\hline
\end{tabular}

\begin{tabular}{|c|c|c|c|c|c|c|c|}
\hline \multicolumn{8}{|c|}{ Parameter Estimates } \\
\hline & & \multirow[b]{2}{*}{ Estimate } & \multirow[b]{2}{*}{$\begin{array}{l}\text { Std. } \\
\text { Error }\end{array}$} & \multirow[b]{2}{*}{ Wald } & \multirow[b]{2}{*}{ Sig. } & \multicolumn{2}{|c|}{$95 \%$ CI } \\
\hline & & & & & & $\begin{array}{l}\text { Lower } \\
\text { Bound }\end{array}$ & $\begin{array}{l}\text { Upper } \\
\text { Bound }\end{array}$ \\
\hline \multirow{2}{*}{ 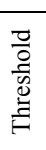 } & $\begin{array}{l}\text { [Personal_ } \\
\text { development }=1]\end{array}$ & -1.628 & 0.219 & 55.296 & 0.000 & -2.058 & -1.199 \\
\hline & $\begin{array}{l}\text { [Personal_ } \\
\text { development }=2]\end{array}$ & 0.206 & 0.170 & 1.462 & 0.227 & -0.128 & 0.540 \\
\hline \multirow{2}{*}{ 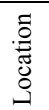 } & Orphan & -0.903 & 0.459 & 3.872 & 0.049 & -1.802 & -0.004 \\
\hline & Low_family_income & 0.753 & 0.407 & 3.418 & 0.065 & -0.045 & 1.551 \\
\hline
\end{tabular}

\begin{tabular}{|c|c|c|c|c|c|c|}
\hline Coefficients. Dependent Variable: PDV \\
\hline \multirow{3}{*}{ Model } & \multicolumn{2}{|c|}{$\begin{array}{c}\text { Unstandardized } \\
\text { Coefficients }\end{array}$} & $\begin{array}{c}\text { Standardized } \\
\text { Coefficients }\end{array}$ & \multirow{2}{*}{ t } & \multirow{2}{*}{ Sig. } & \multicolumn{2}{|c|}{$\begin{array}{c}\text { Collinearity } \\
\text { Statistics }\end{array}$} \\
\cline { 2 - 4 } & B & $\begin{array}{c}\text { Std. } \\
\text { Error }\end{array}$ & Beta & & $\begin{array}{c}\text { Toleran } \\
\text { ce }\end{array}$ & VIF \\
\hline
\end{tabular}


Mihail-Dumitru Sacală, Simona Roxana Pătărlăgeanu, Maria-Floriana Popescu, Marius Constantin

\begin{tabular}{|c|c|c|c|c|c|c|c|}
\hline \hline (Constant) & 2.286 & 0.062 & & 36.849 & 0.000 & & \\
\hline PLV & -0.364 & 0.177 & -0.154 & -2.058 & 0.041 & 0.991 & 1.009 \\
\hline LSI & 0.294 & 0.148 & 0.149 & 1.987 & 0.048 & 0.991 & 1.009 \\
\hline
\end{tabular}

Model IV: Professional development analysis (PFDV). Link function: Logit.

\begin{tabular}{|c|c|c|c|c|c|c|c|c|c|}
\hline \multicolumn{10}{|c|}{ Model Fitting Information } \\
\hline \multicolumn{4}{|c|}{ Model } & \multicolumn{3}{|c|}{-2 Log Likelihood } & $\chi^{2}$ & df & Sig. \\
\hline \multicolumn{4}{|c|}{ Intercept Only } & \multicolumn{3}{|c|}{40.477} & & & \multirow[b]{2}{*}{0.006} \\
\hline \multicolumn{4}{|c|}{ Final } & \multicolumn{3}{|c|}{30.195} & & 10.283 & \\
\hline \multicolumn{10}{|c|}{ Goodness-of-Fit } \\
\hline \multicolumn{4}{|c|}{ Model } & \multicolumn{3}{|l|}{$\chi^{2}$} & \multicolumn{2}{|l|}{ df } & Sig. \\
\hline \multicolumn{4}{|c|}{ Pearson } & \multicolumn{3}{|c|}{4.501} & \multicolumn{2}{|l|}{4} & 0.342 \\
\hline \multicolumn{4}{|c|}{ Deviance } & \multicolumn{3}{|c|}{4.889} & \multicolumn{2}{|l|}{4} & 0.299 \\
\hline \multicolumn{10}{|c|}{ Pseudo $\mathbf{R}^{2}$} \\
\hline \multicolumn{4}{|c|}{ Cox and Snell } & \multicolumn{6}{|c|}{0.057} \\
\hline \multicolumn{4}{|c|}{ Nagelkerke } & \multicolumn{6}{|c|}{0.069} \\
\hline \multicolumn{4}{|c|}{ McFadden } & \multicolumn{6}{|c|}{0.034} \\
\hline Par & imeter $\mathbf{E}$ & imates & & & & & & & \\
\hline & & & & & & & & $95 \%$ & o CI \\
\hline & & & Est & imate & $\begin{array}{l}\text { Std. } \\
\text { Error }\end{array}$ & Wald & Sig. & $\begin{array}{l}\text { Lower } \\
\text { Bound }\end{array}$ & $\begin{array}{l}\text { Upper } \\
\text { Bound }\end{array}$ \\
\hline$\frac{7}{0}$ & $\begin{array}{l}\text { [Profess } \\
\text { develop }\end{array}$ & $\left.\mathrm{ent}_{-}=1\right]$ & & .567 & 0.453 & 11.945 & 1 & 0.001 & -2.456 \\
\hline 总 & $\begin{array}{l}\text { [Profess } \\
\text { develop }\end{array}$ & ent $=2]$ & & 517 & 0.412 & 1.573 & 1 & 0.210 & -0.291 \\
\hline . & $\begin{array}{l}\text { Desire_ } \\
\text { employ }\end{array}$ & & & 177 & 0.376 & 9.815 & 1 & 0.002 & 0.441 \\
\hline 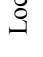 & Knowle & ge_desire & & 579 & 0.394 & 2.163 & 1 & 0.141 & -0.193 \\
\hline & fficients & Depend & t Varia & ole: $\mathbf{P}$ & DV & & & & \\
\hline & Iodel & $\begin{array}{r}\text { Unstan } \\
\text { Coef }\end{array}$ & $\begin{array}{l}\text { ardized } \\
\text { ients }\end{array}$ & $\begin{array}{r}\text { Sta } \\
\text { Co }\end{array}$ & $\begin{array}{l}\text { dardized } \\
\text { fficients }\end{array}$ & & Si & $\begin{array}{r}\text { Coll } \\
\text { St: }\end{array}$ & $\begin{array}{l}\text { linearity } \\
\text { atistics }\end{array}$ \\
\hline & lodei & B & $\begin{array}{c}\text { Std. } \\
\text { Error }\end{array}$ & & Beta & $\mathbf{t}$ & $\mathbf{S I g}$ & $\begin{array}{l}\text { Tole- } \\
\text { rance }\end{array}$ & VIF \\
\hline & nstant) & 2.240 & 0.123 & & & 18.275 & 0.0 & & \\
\hline & PLV & 0.158 & 0.115 & & 0.116 & 1.379 & $0.1^{\prime}$ & 0.758 & 1.319 \\
\hline & LSI & 0.369 & 0.108 & & 0.289 & 3.421 & 0.0 & 0.758 & 1.319 \\
\hline
\end{tabular}

